\title{
Correction to: New Specimens of Reigitherium bunodontum from the Late Cretaceous La Colonia Formation, Patagonia, Argentina and Meridiolestidan Diversity in South America
}

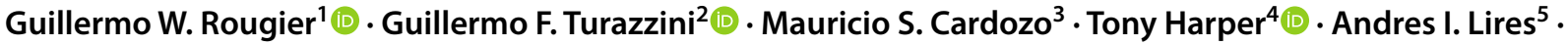 \\ Leandro A. Canessa ${ }^{6}$
}

Published online: 27 December 2021

(c) Springer Science+Business Media, LLC, part of Springer Nature 2021

\section{Correction to: Journal of Mammalian Evolution (2021) 28:1051-1081 https://doi.org/10.1007/s10914-021-09585-2}

The original article was published online with two incorrect specimen numbers. On top of page five, under the title of "Newly referred specimens", number MPEF 2421 should be MPEF 2390 and MPEF 2419 should be MPEF 2396, as in the rest of the paper. In addition, the surname of coauthor Guillermo F. Turazzini was incorrectly spelled as Guillermo F. Turazzinni.

The original article can be found online at https://doi.org/10.1007/ s10914-021-09585-2.

Guillermo W. Rougier

grougier@louisville.edu

1 Department of Anatomical Sciences and Neurobiology,

University of Louisville, Louisville, KY, USA

2 Instituto de Geociencias Básicas,

Ciudad Autónoma de Buenos Aires, Argentina

3 Facultad de Ciencias Naturales Y Museo, Universidad Nacional de La Plata, La Plata, Buenos Aires, Argentina

4 DeBusk School of Osteopathic Medicine, Lincoln Memorial University, Knoxville, TN, USA

5 Departamento de Ecología Genética Y Evolución, EGEBA (CONICET/UBA), UBA,

Ciudad Autónoma de Buenos Aires, Argentina

6 Museo Paleontológico Egidio Feruglio, Trelew, Chubut, Argentina 